\title{
Management of Ilio-Femoral Deep Vein Thrombosis: A Hybrid Approach
}

Anastasia Dean*, Swee Leong Yap and Venu Bhamidipaty

Department of Vascular Surgery, Western Hospital, Gordon Street, Footscray VIC, 3011, Australia

*Corresponding author: Anastasia Dean, Western Hospital, Gordon Street, Footscray VIC, 3011, Australia, Tel: +61(3) 8345 6333; Fax: +61 (3) 83456954; E-mail: anastasiaedean@gmail.com

Rec date: Mar 08, 2014, Acc date: Apr 17, 2014; Pub date: Apr 19, 2014

Copyright: $\odot 2014$ Dean A, et al. This is an open-access article distributed under the terms of the Creative Commons Attribution License, which permits unrestricted use, distribution, and reproduction in any medium, provided the original author and source are credited.

\begin{abstract}
Despite recent innovations in clot lysis technology, management of acute ilio-femoral Deep Vein Thrombosis (DVT) remains a challenge worldwide. We revisit the work of a previous generation of vascular surgeons who created a temporary Arteriovenous Fistula (AVF) in combination with a surgical thrombectomy, to maximize blood flow through the newly revascularized vessel. Since this time, surgical thrombectomy along with the use of a temporary AVF, has been superseded by endovascular techniques: namely Catheter-Directed Thrombolysis (CDT) and Pharmacomechanical Thrombolysis (PMCT). We review the evolution of the management of ilio-femoral deep vein thrombosis, specifically examining the trials which investigate temporary AVF with surgical thrombectomy. Furthermore, we describe the surgical technique of creating a temporary AVF, including how to avoid venous hypertension and how to facilitate closure if required. Finally, in the age of hybrid techniques, we propose that a temporary AVF could be used in combination with current thrombus removal techniques to possibly lower the risk of recurrent thrombosis and complications such as post-thrombotic syndrome.
\end{abstract}

Keywords: Abdominal compartment syndrome; Complicated intraabdominal infection; Intestinal perforation; Ruptured abdominal aortic aneurysm

\section{Introduction}

Despite recent innovations in clot lysis technology, management of acute iliofemoral Deep Vein Thrombosis (DVT) remains a challenge worldwide. Long-term complications of proximal DVT include Postthrombotic Syndrome (PTS), which is characterized by chronic limb heaviness, pain, swelling, paraesthesia, pruritis and pigmentation changes [1,2]. PTS affects between $23-43 \%$ of patients and has been shown to have a significant negative impact on quality of life and a large economic burden on the wider community [3-7]. Early active treatment to remove thrombus has been shown to result in better outcomes, including lower rates of venous valve dysfunction [8], recurrent DVT [9] and PTS [10-12].

\section{Pathology Of Thrombus Formation: Virchow's Triad}

Our current understanding of thrombus formation as a triad of dysfunction of vessel wall, blood flow and blood components was first hypothesized by Rudolf Virchow in 1856 [13]. Firstly, thrombosis can result from an imbalance in the coagulation cascade as a result of inherited and/or acquired molecular defects [14]. Secondly, disruption of blood flow slows the inflow of clotting factor inhibitors, prevents activated clotting factors from dispersing, and allows platelets to come into contact with the endothelium. Thirdly, endothelial injury exposes the thrombogenic sub-endothelial extra-cellular matrix, leading to adhesion and activation of platelets, and the exposure of tissue factor, which activates the coagulation cascade [15]. Importantly, whereas once the endothelium was thought of as a "cellophane wrapper" covering the vasculature, we now understand that endothelial cells play a vital regulatory role in the balance between haemostasis and blood fluidity - even a small perturbation can activate the endothelial cells, with tumour necrosis factor suppressing the formation of thrombomodulin and inducing the expression of tissue factor, tipping the balance in favour of haemostasis and thrombosis [16].

Thrombus-related damage to the endothelial-lined venous valves more than doubles the risk of both valvular incompetence and recurrent venous thrombosis $[9,17]$. Although the exact mechanism of the damage is unclear, it is likely that early valvular incompetence is due to inflammation and recanalization. Conversely, late-onset valvular incompetence is likely due to persistent outflow obstruction and chronic venous ambulatory hypertension. Interestingly, there is also an increase in valvular incompetence in the surrounding nonaffected veins, which is likely to be a result of venous hypertension causing dilatation of the vessel and the separation of the valve leaflets [17]. In the investigation of both chronic thrombosis and valvular incompetence, and suspected acute thrombosis in the lower limb, Doppler and B-mode ultrasound studies have been shown to be highly accurate, objective, reproducible and cost effective $[18,19]$.

\section{Current Management: Anticoagulation}

For an unprovoked DVT of the proximal lower limb, current guidelines of the American College of Chest Physicians recommend early oral anticoagulation and continuation of parenteral anticoagulation with unfractionated heparin, low-molecular weight heparin or fondaparinux for five days or until the International Normalized Ratio (INR) is 2.0 or above for more than 24 hours [12]. For both first and recurrent unprovoked events, the guidelines recommend three months of anticoagulation therapy for patients with a high bleeding risk and extended anticoagulation therapy for patients with a low to moderate bleeding risk [12]. If a patient has a contraindication to anticoagulation, the use of an inferior vena cava filter is recommended [12]. Adjuvant therapies such as mechanical thrombectomy, Catheter-Directed Thrombolysis (CDT) and Pharmacomechanical Thrombolysis (PMCT), act to reduce the thrombus load and restore blood flow. 


\section{A Review of Clot Lysis Techniques}

Surgical thrombectomy for acute iliofemoral venous thrombosis was first reported by Läwen in 1937 [20]. By the 1960s, it was being widely performed in the US $[21,22]$. A damning study published by Lansing and Davis in 1968 [23], however, virtually stopped the practice. In this study, the authors reviewed 17 patients who had undergone surgical thrombectomy for acute DVT five years prior. They reported leg swelling in 16 of 17 patients and incompetent valves in the affected area in 15 of 17 patients. Their study was critically flawed: only 17 of the original 34 study participants had been interviewed; and the venography was performed with patients in a supine position, which cannot accurately assess incompetency of valves [20]. Despite this, very few surgical thrombectomies were performed in the United States after this report; the practice continued only in a few European centres.

From the late 1960s, systemic thrombolysis was being trialled for the management of iliofemoral DVT. With this procedure, patients received an intra-venous infusion of Urokinase (UK), Streptokinase (SK) or recombinant tissue Plasminogen-Activator (rt-PA) for three to seven days. Most trials comparing systemic thrombolysis to conventional anticoagulation reported more cases of complete or partial resolution of clot with systemic thrombolysis, with approximately $50-70 \%$ of patients having some degree of lysis [24]. These positive results were offset by an increased risk of bleeding - the risk of major bleeding $13.2 \%$ compared to $3.5 \%$ in patients treated with heparin [25].

Catheter-Directed Thrombolysis (CDT) developed in response to the unacceptably high risk of bleeding reported with systemic thrombolysis. In CDT, a smaller dose of thrombolytic agent is injected via a catheter device directly into the thrombus. Trials have shown positive results in terms of clot lysis and a more acceptable risk of major bleeding and mortality $[26,27]$. Newer catheter devices, such as the Trellis-8 Peripheral Infusion System ${ }^{\mathrm{m}}$ (Covidien Inc., Mansfield, MA) and the AngioJet Rheolytic Thrombectomy System ${ }^{\text {Tw }}$ (Medrad Interventional - Bayer, Minneapolis, Minnesota) have an additional mechanical function, which acts to macerate the clot, thus increasing contact of lytic agent with clot and accelerating clearance [28-30]. The Trellis-8 Infusion Catheter System ${ }^{\text {Tn }}$ consists of a single-use catheter device with two occlusive balloons $(5-16 \mathrm{~mm})$ and a sinusoidal-shaped nitinol 'dispersion' wire connected to a pump via a Luer-Lok [31,32]. The two occlusive balloons are inflated proximally and distally to the target area, isolating the infusion of the thrombolytic agent. When in use, the dispersion wire rotates, causing the catheter to oscillate at 500-3500 rpm, dispersing the lytic agent and mechanically disrupting the clot. After which, fragments of the clot are suctioned out. The AngioJet $^{\text {tix }}$ system includes a single-use, fenestrated catheter, connected to a pump set and a drive set [33]. As the catheter is passed through the thrombus, a high-power jet of thrombolytic agent is pulsed through the catheter fenestrations, causing an area of low pressure at the catheter tip. After thirty minutes, the catheter is again passed through the clot, aspirating the macerated clot via the efferent tube. Current evidence for these devices, termed Pharmacomechanical Thrombolysis (PMCT) is sparse - a large multi-centre randomized controlled trial (ATTRACT) is ongoing [30,34].

\section{Is the Management of Stasis Standing Still?}

Despite extensive evidence linking stasis to the development of thrombosis, intervention to maximise blood flow in the management of iliofemoral DVT is the least studied. Normal blood flow is laminar, in which platelets travel centrally in the vessel lumen, separated from the endothelium by a slower flowing clear zone of plasma. Stasis disrupts laminar flow, bringing platelets into contact with the endothelium. It also prevents dilution of activated clotting factors, retards the inflow of clotting factor inhibitors and permits the buildup of thrombi, thereby promoting endothelial cell activation, resulting in local thrombosis and leukocyte adhesion. A recent study has shown that there is a significant increase in plasma interleukin-6 (IL-6), endothelin-1 (ET-1) and Angiotensin II (ATII) in acute peripheral venous congestion [35]. The endothelial-lined bicuspid valves in the venous system are also exposed to disturbed blood flow and reduced shear stress during the normal valve cycle [36]. In fact, blood has been shown to remain stagnant for up to 27 minutes in the valve sinuses in the leg, which becomes relatively hypoxic, inflaming the underlying endothelial cells $[37,38]$.

Clinical evidence for stasis as a contributor of DVT is manifold: there is a higher incidence of DVT in the paralyzed leg compared to the active leg in hemiplegic patients; institutionalisation - either in hospital or nursing home residences - is attributable for $59 \%$ of DVT in community; and hospitalized medical and surgical patients experience an equal proportion of DVT [39]. Given the causal role of stasis in thrombus formation, it follows that blood flow is vital in preventing thrombus formation and re-thrombosis post-clot clearance. Therein lies an opportunity to maximize treatment of acute iliofemoral DVT - to actively increase blood-flow by constructing a temporary arteriovenous fistula (AVF) distal to the target site.

\section{Arteriovenous Fistulae and Iliofemoral DVT}

Following the Lansing and Davis study, some European centres continued to perform surgical thrombectomies for acute iliofemoral DVTs [40-45]. The following two decades saw considerable change in the practice: superior non-invasive imaging; the introduction of the Fogarty catheter; the combination of a temporary AVF with thrombectomy; intra-operative venography; and a longer postoperative course of anticoagulation [23].

European studies at the time were small and non-randomised. Juhan et al. [46] reviewed 77 lower extremities after surgical thrombectomy and temporary AVF for acute DVT and reported $84 \%$ vessel patency with valvular competence at $80 \%$ at 5 years, dropping to $56 \%$ at 10 years.

Plate et al. [47] followed-up thirty patients ten years after a prospective, randomised study comparing surgical thrombectomy/ temporary AVF and conventional anticoagulation treatment with anticoagulation alone. In the intervention arm, leg swelling was seen in six patients (46\%), and lower limb ulceration in one (8\%), compared to $12(71 \%)$ and three (18\%) patients respectively in the conventional arm. These results were not statistically significant given the small numbers. In the same study, radionuclide angiography showed that the iliac vein was more commonly occluded following conservative treatment $(59 \%)$ than surgical intervention $(17 \%)(p<0.05)$. The researchers concluded, therefore, that venous thrombectomy improves patency and could potentially reduce venous reflux and postthrombotic sequelae.

Swedenborg et al. [41] evaluated 17 patients after venous thrombectomy combined with a temporary AVF - the primary surgery was unsuccessful in two patients who had chronic occlusion of iliac veins. At three months, 14 patients had a patent iliac vein. After a 
mean follow-up of 38 months, eight patients had a patent iliac vein eight had partial reconstitution, and three had an occluded iliac vein.

Thirty patients were evaluated post-venous thrombectomy with temporary AVF by Meissner [48]. In this study, the temporary AVF was closed 8 to 12 weeks after its creation. Three patients died during early the post-operative period: one due to cardiogenic shock secondary to massive myocardial infarction, and two from septic shock. Of the remaining 27 patients, complete patency of iliofemoral veins was achieved during the operation in all, and none of the patients had signs of re-thrombosis within 30 days. At one year postfistula closure, moderate leg swelling was noted in 16 patients, however no patients experienced ulceration or re-thrombosis.

In summary, these studies, although small, yielded consistently favourable results. Despite this, the use of a temporary AVF with thrombectomy is still out of favour along with surgical thrombectomy. In an age of hybrid solutions, a temporary AVF could be beneficial when used in combination with CDT/PMCT to minimize the potential for re-thrombosis.

\section{Arterio-Venous Fistulae: Surgical Technique}

An AVF can be constructed by end-to-side anastomosis using the end of proximal saphenous vein or preferably a large proximal branch of the saphenous vein anastomosed to the side of the proximal superficial femoral artery or profunda femoris with the anastomosis limited to 3.5 to $4.0 \mathrm{~mm}$ in diameter [49]. Then, a wrap of polyethylene or silastic can be placed around the saphenous AVF. Finally, a large permanent monofilament suture is looped around the wrapped vein and clipped with approximately $2 \mathrm{~cm}$ left in the subcutaneous tissue to guide future dissection if operative closure of the AVF is necessary.

While some researchers have reported closure of the AVF by percutaneous balloon occlusion [50-52], most patients do not require closure as flow through the small AVF diminishes with time because of neo-intimal fibroplasia [49]. If closure of the AVF is necessary, it is commonly performed after $4-8$ weeks $[46,47]$. The common femoral vein pressure is measured before and after the AVF is opened. The venous pressure should not increase when the AVF is flowing elevation of venous pressure on opening AVF dictates the need for proximal iliac vein re-evaluation for residual stenosis or obstruction and correction of any proximal lesion. In cases of persistent increased pressure, the AVF should be constricted to decrease flow and normalise pressure [53] or even ligated to prevent iatrogenic venous hypertension.

\section{Conclusion}

The management of acute iliofemoral deep vein thrombosis is constantly evolving. Clot removal techniques, such as surgical thrombectomy and thrombolysis, have been shown to be superior to anticoagulation therapy alone, resulting in decreasing rates of postthrombotic syndrome and DVT recurrence. Nonetheless, there is still a considerable disease burden in the community. In the search for better patient outcomes, we revisit the work of a previous generation of vascular surgeons who created a temporary AVF in combination with a surgical thrombectomy to promote blood flow through the newly re-vascularized vessel. A number of small studies support their work, presenting consistently positive results. We propose that a temporary AVF could be beneficial when used in combination with anticoagulation therapy and CDT or PMCT. A temporary AVF is a simple technique to perform with minimal risk to the patient, and great potential to prevent re-thrombosis and PTS. We believe further investigation is warranted to test this hypothesis.

\section{References}

1. Kahn SR, Partsch H, Vedantham S, Prandoni P, Kearon C; Subcommittee on Control of Anticoagulation of the Scientific and Standardization Committee of the International Society on Thrombosis and Haemostasis (2009) Definition of post-thrombotic syndrome of the leg for use in clinical investigations: a recommendation for standardization. J Thromb Haemost 7: 879-883.

2. Kahn SR, Hirsch A, Shrier I (2002) Effect of postthrombotic syndrome on health-related quality of life after deep venous thrombosis. Arch Intern Med 162: 1144-1148.

3. Prandoni P, Lensing AW, Cogo A, Cuppini S, Villalta S, et al. (1996) The long-term clinical course of acute deep venous thrombosis. Ann Intern Med 125: 1-7.

4. Kahn SR, Shrier I, Julian JA, Ducruet T, Arsenault L, et al. (2008) Determinants and time course of the postthrombotic syndrome after acute deep venous thrombosis. Ann Intern Med 149: 698-707.

5. Delis KT, Bountouroglou D, Mansfield AO (2004) Venous claudication in iliofemoral thrombosis: long-term effects on venous hemodynamics, clinical status, and quality of life. Ann Surg 239: 118-126.

6. Kahn SR, Ducruet T, Lamping DL, Arsenault L, Miron MJ, et al. (2005) Prospective evaluation of health-related quality of life in patients with deep venous thrombosis. Arch Intern Med 165: 1173-1178.

7. Kachroo S, Boyd D, Bookhart BK, LaMori J, Schein JR, et al. (2012) Quality of life and economic costs associated with postthrombotic syndrome. Am J Health Syst Pharm 69: 567-572.

8. van Haarst EP, Liasis N, van Ramshorst B, Moll FL (1996) The development of valvular incompetence after deep vein thrombosis: a 7 year follow-up study with duplex scanning. Eur J Vasc Endovasc Surg 12: 295-299.

9. Prandoni P, Lensing AW, Prins MH, Bernardi E, Marchiori A, et al. (2002) Residual venous thrombosis as a predictive factor of recurrent venous thromboembolism. Ann Intern Med 137: 955-960.

10. van Rij AM, Hill G, Krysa J, Dutton S, Dickson R, et al. (2013) Prospective study of natural history of deep vein thrombosis: early predictors of poor late outcomes. Ann Vasc Surg 27: 924-931.

11. Comerota AJ, Grewal N, Martinez JT, Chen JT, Disalle R, et al. (2012) Postthrombotic morbidity correlates with residual thrombus following catheter-directed thrombolysis for iliofemoral deep vein thrombosis. J Vasc Surg 55: 768-773.

12. Kearon C, Akl EA, Comerota AJ, Prandoni P, Bounameaux H, et al. (2012) Antithrombotic therapy for VTE disease, antithrombotic therapy and prevention of thrombosis (9thedtn) American College of Chest Physicians Evidence-Based Clinical Practice Guidelines. Chest 141:419S-94S.

13. Bagot CN, Arya R (2008) Virchow and his triad: a question of attribution. Br J Haematol 143: 180-190.

14. Thomas RH (2001) Hypercoagulability syndromes. Arch Intern Med 161: 2433-2439.

15. Kumar V, Abbas AK, Fausto N (2004) Robbins and Cotran Pathologic Basis of Disease. (7thedtn), Elsevier Saunders, Philadelphia.

16. Rajendran P1, Rengarajan T, Thangavel J, Nishigaki Y, Sakthisekaran D, et al. (2013) The vascular endothelium and human diseases. Int J Biol Sci 9: 1057-1069.

17. Caps MT, Manzo RA, Bergelin RO, Meissner MH, Strandness DE Jr (1995) Venous valvular reflux in veins not involved at the time of acute deep vein thrombosis. J Vasc Surg 22: 524-531.

18. Galeandro AI, Quistelli G, Scicchitano P, Gesualdo M, Zito A, et al. (2012) Doppler ultrasound venous mapping of the lower limbs. Vasc Health Risk Manag 8: 59-64. 
19. Lensing AW, Prandoni P, Brandjes D, Huisman PM, Vigo M, et al. (1989) Detection of deep-vein thrombosis by real-time B-mode ultrasonography. N Engl J Med 320: 342-345.

20. Eklöf B (2011) Surgical thrombectomy for iliofemoral venous thrombosis revisited. J Vasc Surg 54: 897-900.

21. MahorneR H, Castleberry JW, Coleman WO (1957) Attempts to restore function in major veins which are the site of massive thrombosis. Ann Surg 146: 510-522.

22. Haller JA Jr, Abrams BL (1963) Use Of Thrombectomy in the Treatment of Acute Iliofemoral Venous Thrombosis in Forty-Five Patients. Ann Surg 158: 561-569.

23. Lansing AM, Davis WM (1968) Five-year follow-up study of iliofemoral venous thrombectomy. Ann Surg 168: 620-628.

24. Janssen MC, Wollersheim H, Schultze-Kool LJ, Thien T (2005) Local and systemic thrombolytic therapy for acute deep venous thrombosis. Neth Med 63: 81-90.

25. Hirsch J, Lensing AW (1996) Thrombolytic therapy for deep vein thrombosis. Int Angiol 5: S22-S25.

26. Mewissen MW, Seabrook GR, Meissner MH, Cynamon J, Labropoulos $\mathrm{N}$, et al. (1999) Catheter-directed thrombolysis for lower extremity deep venous thrombosis: report of a national multicenter registry. Radiology 211: 39-49.

27. Enden T, Haig Y, Kløw NE, Slagsvold CE, Sandvik L et al. (2012) Longterm outcome after additional catheter-directed thrombolysis versus standard treatment for acute iliofemoral deep vein thrombosis (the CaVenT study): a randomised controlled trial. Lancet 379:31-38.

28. Rao AS, Konig G, Leers SA, Cho J, Rhee RY, et al. (2009) Pharmacomechanical thrombectomy for iliofemoral deep vein thrombosis: an alternative in patients with contraindications to thrombolysis. J Vasc Surg 50: 1092-1098.

29. Arko FR, Arko MZ, Murphy EH (2011) Endovascular intervention for lower extremity deep vein thrombosis. Vasc Dis Manag 8: 71-79.

30. Vedantham S, Goldhaber SZ, Kahn SR, Julian J, Magnuson E, et al (2013) Rationale and design of the ATTRACT Study: a multicenter randomized trial to evaluate pharmacomechanical catheter-directed thrombolysis for the prevention of postthrombotic syndrome in patients with proximal deep vein thrombosis. Am Heart J 165:523-530.

31. Krajcer Z, Atmakuri SR (2006) One-step treatment of DVT with the Trellis-8 Device. Endovascular Today April: 69-74.

32. O'Sullivan GJ, Lohan DG, Gough N, Cronin CG, Kee ST (2007) Pharmacomechanical thrombectomy of acute deep vein thrombosis with the Trellis-8 isolated thrombolysis catheter. J Vasc Interv Radiol 18: 715-724.

33. Kasirajan K, Gray B, Ouriel K (2001) Percutaneous AngioJet thrombectomy in the management of extensive deep venous thrombosis. J Vasc Interv Radiol 12: 179-185.

34. Wysokinska EM, Sobande F, Wysokinski WE, Bjarnason H, McBane RD (2010) Iliac vein thrombosis: feasibility assessment of randomized controlled trials of endovascular pharmacomechanical thrombolysis. J Thromb Haemost 8:1943-1949.
35. Colombo PC, Onat D, Harxhi A, Demmer RT, Hayashi Y, et al. (2014) Peripheral venous congestion causes inflammation, neurohormonal, and endothelial cell activation. Eur Heart J 35: 448-454.

36. Chiu JJ, Chien S (2011) Effects of disturbed flow on vascular endothelium: pathophysiological basis and clinical perspectives. Physiol Rev 91: 327-387.

37. Mclachlin AD, Mclachlin JA, Jory TA, Rawling EG (1960) Venous stasis in the lower extremities. Ann Surg 152: 678-685.

38. Hamer JD, Malone PC, Silver IA (1981) The PO2 in venous valve pockets: its possible bearing on thrombogenesis. Br J Surg 68: 166-170.

39. Warlow C, Ogston D, Douglas AS (1976) Deep venous thrombosis of the legs after strokes. Part I--incidence and predisposing factors. Br Med J 1: 1178-1181.

40. Plate G, Einarsson E, Ohlin P, Jensen R, Qvarfordt P, et al. (1984) Thrombectomy with temporary arteriovenous fistula: the treatment of choice in acute iliofemoral venous thrombosis. J Vasc Surg 1: 867-876.

41. Swedenborg J, Hägglöf R, Jacobsson H, Johansson J, Johnsson H, et al. (1986) Results of surgical treatment for iliofemoral venous thrombosis. Br J Surg 73: 871-874.

42. Stirnemann P, Althaus U, Kirchhof B, Triller J, Nachbur B, et al. (1984) Early phlebographic results after iliofemoral venous thrombectomy. Thorac Cardiovasc Surg 32: 299-303.

43. Røder OC, Lorentzen JE, Hansen HJ (1984) Venous thrombectomy for iliofemoral thrombosis. Early and long-term results in 46 consecutive cases. Acta Chir Scand 150: 31-34.

44. Goto H, Wada T, Matsumoto A, Matsumura H, Soma T (1980) Iliofemoral venous thrombectomy (follow-up studies of 88 patients). J Cardiovasc Surg (Torino) 21: 341-346.

45. Lerut J, Sandmann W (1982) Reevaluation of surgical therapy in acute deep venous thrombosis of the lower limbs. Acta Chir Belg 82: 59-66.

46. Juhan CM, Alimi YS, Barthelemy PJ, Fabre DF, Riviere CS (1997) Late results of iliofemoral venous thrombectomy. J Vasc Surg 25: 417-422.

47. Plate G, Eklöf B, Norgren L, Ohlin P, Dahlström JA (1997) Venous thrombectomy for iliofemoral vein thrombosis--10-year results of a prospective randomised study. Eur J Vasc Endovasc Surg 14: 367-374.

48. Meissner AJ, Huszcza S (1996) Surgical strategy for management of deep venous thrombosis of the lower extremities. World J Surg 20: 1149-1155.

49. Comerota AJ, Gale SS (2006) Technique of contemporary iliofemoral and infrainguinal venous thrombectomy. J Vasc Surg 43: 185-191.

50. Endrys J, Eklöf B, Neglén P, Zýka I, Peregrin J (1989) Percutaneous balloon occlusion of surgical arteriovenous fistulae following venous thrombectomy. Cardiovasc Intervent Radiol 12: 226-229.

51. Neglén P, al-Hassan HK, Endrys J, Nazzal MM, Christenson JT, et al. (1991) Iliofemoral venous thrombectomy followed by percutaneous closure of the temporary arteriovenous fistula. Surgery 110: 493-499.

52. Eklof B (2000) Arteriovenous fistulas as an adjunct to venous surgery. Semin Vasc Surg 13: 20-26.

53. Comerota AJ (2012) The current role of operative venous thrombectomy in deep vein thrombosis. Semin Vasc Surg 25: 2-12. 